\title{
ATTITUDE AND LEARNING MOTIVATION ON ARABIC LEARNING IN MUSLIM MINORITY OF NORTH SULAWESI
}

\author{
Ismail Suardi Wekke*, Suhendar** \\ *State Islamic College (STAIN) of Sorong \\ **State Islamic University (UIN) of Sunan Gunung Djati, Bandung \\ Email: iswekke@gmail.com
}

Paper Presented in

The International Conference Arabic Language Education and Literature and Islamic Values between Expectation and Realization

Bandung, 11-12 November 2016

\begin{abstract}
Arabic is compulsory subject listed on Islamic studies issue. Over the years, students learn Arabic as the main subject. In addition, Arabic subject integrates through many subject. Therefore, it is a need to discover the standing of attitude and motivation on Arabic learning. The two factors among the pillar in maintaining teaching and learning of Arabic. On the other hand, Muslim minority environment is a unique condition to maintain the Arabic teaching and learning training. The research was conducted in North Sulawesi, Indonesia. The picture of muslim minority indicates a dynamic situation. Different existence from other muslim part of Indonesia shows the opportunity to rely on co-exist to multicultural. This research is initial study to explore the relationship between attitudes in learning language. The age of learner influences their struggle and spirit in learning the resources language. Motivation provides the main driving for student during the process of learning. Eventough they are part from family and stay in the boarding school for over the academic term. Moreover, this article discuses that attitude and motivation are among the main factor learning Arabic language. High motivation deliver considerable environment during school time. Student attitude and motivation is not a single form. There are many factors and conditions represent to the complexity of the situation. The findings implicate many aspect of teaching and learning. Indeed, motivation for learning target language is the source to sustain the process on the different aspects of teaching. Finally, there are many suggestions and recommendations for further study on the end part of article.
\end{abstract}

Keyword: motivation, attitude, environment, Arabic

\section{INTRODUCTION}

Language learning could not be inevitably separated from the factor of personal learning. Indeed, it becomes salient indicator of the success of foreign language learning. Inherent personality attached in each individual can be constructed and thus could assist the learning process. Moreover, the constructed personality in each individual, become a basis of Arabic learning. Through this such subjective perspective, the development of language 
proficiency can be established due to distinct personalities in each individual distinguishing one from the others. Starting from cultural conflict, it will become an initial issue once it is not accelerated greatly. Certainly, not all Arab matters are Islam since Islam does not merely necessarily reflect Arab. Thus, through the contextual understanding of culture, it eases students in learning the language. They will never thoroughly master a language if they do not understand the cultural context of the language. Despite the preliminary step, it at least helps them to use the language properly based on its daily use.

Motivation is considered key of success through which it enlivens learning interest despite varied barriers or obstacles faced. Once motivation is mainly taught in initial phase, there will be no obstacle that could stop the learning process.In fact, even students face any obstacles, they would patiently bear them in order to maintain their learning interest. Therefore, giving stimuli to enhance students' learning motivation is as important as the learning materials per se which ultimately guides them to undergo the learning process.

Nevertheless, to design each conceptual theme, it should not be defined empirically as other terms such as empathy, aggression, and other psychology terms. Motivation, as other psychology terms, is hardly defined. It takes serial activities adjusted and integrated one another to establish motivation which thus eventually creates several indicators of motivation. Through the well-planned and adjusted process, both indicators and learning achievement known as motivation will become a part of learning processes. It will enforce the learning process and encourage students to maintain their learning interest.

Heard of the word dangdut, everyone will surely have different perspectives. There may be one who loves it yet seems ashamed of admitting his/her interest, or personally he loves dangdutas his favorite playlist yet once he gets engaged with other community he seems less likely to perceive that he does not love dangdut. It also works on the Arabic learning. Everyone has different perspectives upon the Arabic learning either in terms of 
personal or communal matters. The interest of learning Arabic also stratifies each other and thus establishes distinct perspective upon the Arabic learning.

Every student must have optimism. Due to this optimism, they could bear with any learning barriers or obstacles such as: anxiety, stress, to name just few. Learning is not an easy activity but is not also that difficult to undergo on another side, depending on the surrounding environment. Conversely, if they do not have adequate level of optimism, even small matters could become a great learning obstacle. The students at State Madrasah Aliyah of Model Sorong in facing National Exam 2011 had to bear these learning obstacles. Beside social support from family and surrounding environment, another influential factor assisting them to face the national exam was high level of optimism. There are $66 \%$ of students could obtain high score due to their sustainable exam preparation incorporating learning review, try outs, and private lessons. They all believed that it takes no time for gaiety (Wekke, 2015).

In another context, a learning process without any optimism tends to yield nonoptimal outcomes. Through optimism, their effort will be sustained and constantly strive to achieve the best outcomes.Repeatedly ongoing activities in defined long period of time will create positive enforcement. Once it stops, however, it will decrease students' ability. Thus, it necessarily needs repetition to develop desired behaviors in order to achieve great learning achievement. In other words, learning achievement emerges as the achieved abilities or competences.

\section{PERSONAL PERSPECTIVE ON LANGUAGE}

Motivation becomes a part of each individual. Hence, motivation will become a basic factoraffecting language learning. A student in madrasah, as being asked to reread sentences in the board, he answered "I could not" while other students read it out load. This student who said that he could not read it prefers to lay his back and keep quiet, closing his eyes and 
enjoying his sleep. This such behavior reflects his ignorance towards learning process. In the same case, a student does not bring textbook and other stationaries during the learning process. As being asked, he always answers "forget" while teacher could not respond and then ask "So, what do you remember?". For teacher, this forgetful student seems have no interest to learn in the class.In another occasion, a student does not write the materials due to his lost pen. Suppose, he should have prepared all stationaries before the learning process.

Student's behaviors such as: "unable to read", "forget to bring stationaries", and "does not have a pen" reflect the learning obstacles appeared from their unpreparedness to undergo learning process. It might be acceptable to perceive that everyone ever forgets, yet what student shows during the learning process is rather irrational. Another alternative, they could prepare their stationaries before the learning process and thus could undergo the learning process without any problems. Given a case, they do not have any stationaries, suppose they could borrow them from other students. Meanwhile, for those who said that they could not perform any tasks in the class, it necessarily administers additional training and guidance to cope with these such issues. These all issues might be due to the lack of learning motivation or the absence of particular orientation in the Arabic learning.

Taha - Thomure differentiates motivation in relation to the necessity and motive by classifying it into organic needs and emergency motive (Taha - Thomure, 2008). The organic needs appear depending on an individual's physical conditions or biological properties which significantly relate to the needs of preserving and maintaining the viability of an individual as organism. In comprises hunger, thirst, breathing, safety, sexual needs, and rest activity. Second, the emergency motive appears as an individual faces an emergency condition that needs to be handled very soon, such as: natural disaster, parent's sickness, and other emergency conditions. It also comprises escape motive which is motive to escape from a danger. Incentive of this motive is to get safety and survival. Combat motive is a motive to 
fight against others and defend himself. Effort motive also known as mastery motive is a motive to cope with obstacles. Incentive from these motives is to succeed any work or cope with obstacles. Last, pursuit motive is a motive to pursue or achieve a target in life (Economides, 2008).

Moreover, there are three contradictive perspectives in learning language. All are relevant according to each position. These three perspectives complete each other despite their distinction. Through these perspectives, it creates a language image through which each perspective contributes to the holistic overview. Each provides discrete descriptions and thus offers particular concept in different contexts.

\section{Reflective and Productive}

Language proficiency is measured from the performance on how an individual uses a language in their daily basis. Regarding this, Maslovaty explains there are two performances, namely reflective and productive (Maslovaty, 2002). If an individual could reflect what he has learned for instance imitating words, substitution, and other conventional language trainings, this is what language educator calls as reflective. By using audiolingual method, students could get used to this such performance. Training and guidance done in the class encourage students to master their own model despite initial phase through the use of textbook. Through this model, they could train themselves. These are categorized in productive performances.

Reflective and productive properties relate to students' creativity by which they could distinguish language proficiency (an ability to use the language properly) and performance. The important aspect in this case is the differences between competence (language proficiency) and performance. Ideally, language learning should encompass these two properties and not perceive language as what have been perceived by behaviorists. Language 
proficiency is a competence related to language characteristics cognitively possessed by speaker. Meanwhile, performance is an application of the language competence in understanding (istima), talking (muhadatsah), and writing (kitabah). It means that language proficiency is an essence of performance. The implementation of language proficiency reflects what students have learned. It, however, sometimes goes beyond this competence due to particular factors such as: fatigue, illness, mispronunciation, or miswrite (Mahmoud, 2013).

As these such deviations occur, it purely relates to logic. Students might not have holistic understanding related to concept and therefore could not deliver it fluently. The misuse of words or sentences are purely due to lack of experiences. Language proficiency is indeed a language mastery. A child who grows up in particular language environment will naturally understand the language without any formal learning. Even he does not necessarily need an instruction (Leandro Parreira Duarte, El Rhalibi, \& Merabti, 2014).

\section{Defensive and Receptive}

Two experts together convey dualism on learning attitudes, which are: defensive and receptive learning. Ahmad perceive that there is a predisposition shown by an individual in learning language (Ahmad, 2009). For those who are defensive, they tend to perceive foreign language merely about sounds, words, rules, or patterns taught by teacher or instructor. Teacher is regarded a pierced arrow. Their fear of teacher appears to be unpleasing experience, including fear of making a mistake. They tend to perceive language learning is about rigid rules that should not be violated.

Consequently, they never use or read their textbooks. Sometimes, they just throw them away. There is a heavy burden upon their shoulder while having a learning process. They are unlikely to contribute to the learning process. Instead, they rather avoid the learning process. Curran gives an analogy to the idea of how qualified seeds could not grow on rocks 
or arid soil. Reversely, common seeds could optimally grow on fertile soil compared to the previous qualified seeds. This such analogy reflects the understanding on the receptive learning.

It takes an attempt to develop the receptive learning and minimize the defensive one. Teacher needs a breakthrough to create sustainable and joyful learning process which relates to students' interest. Playing sport is indeed very exhausting activity. Due to their interest in playing sport, however, their fatigue seems likely to be ignored. Even, they tend to repeat the activities. It also goes for language learning. Fatigue has to be ignored since there are a lot of joy during the learning process.

\section{Instrumental and Integrative}

Dinh. Rinfret, Raymond, \& Thi stated that motivation in learning foreign language means instrumental and integrative (Dinh, Rinfret, Raymond, \& Thi, 2013). Instrumental motivation is a desire to master foreign language in order to easily get a job, social appreciation, certificate, or other benefits. Those who learn foreign language will get real benefit. Thus, they usually apply defensive learning style. Meanwhile, integrative motivation is a desire to acquire foreign language in order to integrate with language native. There is personal intention to practice language native. Thus, they usually apply receptive learning style.

Akdede conclusion was derived from 12-year study on foreign language learning in Canada, America, and Philippine (Akdede, 2014). There are several factors that influence motivation on success of learning language. Instrumental factor showed that language acquisition is a tool to achieve instrumental objectives, such as enhancing career, reading technical material, translating, etc. Meanwhile, integrative factor showed that students more likely to integrate to second language group and involve to social interaction. Instrumental 
and integrative factors are not motivation types as stated by Gardner and McIntyre, but orientation. It means those students in a context or orientation related to (1) academic affairs or (2) social and cultural orientation (integrative). Various needs still can be reached in learning foreign language. Therefore, motivation is more likely to increase or decrease based on intensity. An individual who learns a thing initiated by motivation to reach better career and learns language to use it in daily life will get success respectively. However, both of them still have high intensity. It can be stated that orientation is a different part of motivation.

Regarding the integrity, Burdbar Khan \& Nisar Sheikh stated that there is a possible high score of language proficiency test. His study concluded that it needs requirement to get success in learning foreign language (Burdbar Khan \& Nisar Sheikh, 2012). However, it is still questioned. Otherwise, it was proved that Indian students who use Marathi language with instrumental orientation in learning English get a higher score of language proficiency test. Sengupta \& Sarker explained that India is an example of interaction between India and England for many years in which become an important factors that influence learner orientation having instrumental desire (Sengupta \& Sarker, 2011). English in India plays an important role of national interaction. Thus, Indian should master English to interact among them.

\section{Learning Achievement}

To ride a bicycle, a rider does not need to explain all its components. A mechanic has a duty to explain all the components. Because, the main skill required in riding a bicycle is avoiding accident. It seems like learning Arabic. To explain, translate, and make Arabic as learning source becomes advanced skill for certain people. The skill that should be mastered by an individual to learn language is communication. Hence, the use of language is how the language can be a productive tool to create good communication among people. 
Primarily, learning achievement is affected by internal and external factors. Internal factor involves physiological and psychological condition of individual (Nasrallah, 2014). Physiology factor should be concerned by consuming sufficient nutrition. The lack of nutrition will affect on body, such as flu, toothache, cough, etc. Meanwhile, psychology factor involves intelligence, interest, motivation, behavior, concentration, learning style, and personality.

There are several factors that determine learning achievement, namely intelligence, personality, experience, gender, diligence, and motivation (Nath, 2012). However, another individual factor is maturity. It caused due to quantitative and qualitative changes in body structure. Maturity provides certain condition where physiological functions and neuron systems develop rapidly. Age influences the development and growth of human maturity. There is no evidence which explains that gender differences can influence students' skill, interest, behavior, and emotion. Actually, gender is determined by social agreement. Moreover, mental capacity is developed according to physiological function on neuron system. Last, motivation is highly related to need, motive, and objective factors.

External factor consists of social and non-social aspects. Non-social aspect involves learning material, difficulty level, and complexity. The environment covers temperature, air, location, relation with parent, teacher, weather, and time. Moreover, instrumental factors cover school building, curriculum, teacher, learning program, etc. Meanwhile, social aspect involves the existence of social interaction. Culture factor will help an individual to master foreign language including Arabic.

Other factor that influences learning achievement is environment. Wekke showed that the existence of school plays an important role of education development (Yusuf \& Wekke, 2015). Commonly, the achievement of school will affect students' motivation to work hard. As a consequence, the status of school gives motivation and support on learning achievement 
for students. Private school cannot be underestimated in term of achievement. Talking about achievement, in fact, many private schools are greater than public school.

Physical environment involves learning assistant, such as school infrastructure. Particularly, the existence of learning assistant will ease students to achieve successful learning. Otherwise, lack of learning assistant will badly affect on students' achievement. However, learning assistant is not main indicator that influences learning achievement. Hence, it should need teacher involvement to guide students in teaching-learning process.

\section{CONCLUSION}

The skill can be formed through an effort and process toward particular field. It should be associated with self-awareness. Thus, the manifestation of learning is an attempt and process of individual behavior to learn particular skill or competence as a form of selfawareness. Moreover, it should be initiated by internal factor of individual. The achievement cannot be measured by only one indicator, such as being champion. The school usually measures it by considering students' behavior inside and outside the school. The point that can be taken is creating students who are intelligence socially, spiritually, and emotionally in establishing conditional circumstances. Olympiad or competition is an important aspect in learning process. However, it cannot be an indicator to measure students' achievement. This aspect is expected for students' exercise to train their skill and competence. Actually, education is not about winning competition but becoming functional and practical humans in social life who are intelligence socially, emotionally, and spiritually. In short, the students present their selves as holistic personal to live the life.

\section{REFERENCE}

Ahmad, K. (2009). Leadership and work motivation from the cross cultural perspective. International Journal of Commerce and Management, 19(1), 72-84. 
Akdede, S. H. (2014). Development elasticity of religious assets: a Turkish experience. International Journal of Manpower, 35(1/2), 89-102.

Burdbar Khan, M., \& Nisar Sheikh, N. (2012). Human resource development, motivation and Islam. Journal of Management Development, 31(10), 1021-1034.

Dinh, T. Le, Rinfret, L., Raymond, L., \& Thi, B.-T. D. (2013). Towards the reconciliation of knowledge management and e-collaboration systems. Interactive Technology and Smart Education, 10, 95-115.

Economides, A. A. (2008). Culture aware collaborative learning. Multicultural Education \& Technology Journal, 2(4), 243-267.

Leandro Parreira Duarte, R., El Rhalibi, A., \& Merabti, M. (2014). Coarticulation and speech synchronization in MPEG-4 based facial animation. Kybernetes, 43(8), 1165-1182.

Mahmoud, A. (2013). A linguistic perspective of the effect of English on MSA: Manifestations and ramifications. Journal of King Saud University - Languages and Translation, 25(1), 35-43.

Maslovaty, N. (2002). Organizational learning: teachers' perceptions of the "ideal student" trait system. International Journal of Manpower, 23(8), 734-753.

Nasrallah, R. (2014). Learning outcomes' role in higher education teaching. Education, Business and Society: Contemporary Middle Eastern Issues, 7(4), 257-276.

Nath, S. R. (2012). The role of pre-school education on learning achievement at primary level in Bangladesh. International Journal of Early Years Education, 20(1), 4-14.

Sengupta, J., \& Sarker, D. (2011). Caste and religious diversity on human capital outcome: evidence from India. Humanomics, 27(3), 166-183.

Taha-Thomure, H. (2008). The status of Arabic language teaching today. Education, Business and Society: Contemporary Middle Eastern Issues, 1(3), 186-192.

Wekke, I. S. (2015). Arabic Teaching and Learning: A Model From Indonesian Muslim Minority. Procedia - Social and Behavioral Sciences, 191, 286-290.

Yusuf, M., \& Wekke, I. S. (2015). Active Learning on Teaching Arabic for Special Purpose in Indonesian Pesantren. Procedia - Social and Behavioral Sciences, 191, 137-141. 